\title{
Campos do Jordão a procura da hospitalidade urbana
}

Campos do Jordão searching to the urban hospitality

\author{
Valéria Luiza Pereira Fedrizzi \\ Instituto Federal de Educação Ciência e Tecnologia do Estado de São Paulo - IFSP - Campos do Jordão - São Paulo - Brasil
}

\section{Bruna Castro Mendes}

Instituto Federal de Educação Ciência e Tecnologia do Estado de São Paulo - IFSP - Campos do Jordão - São Paulo - Brasil

Resumo: Os estudos da hospitalidade e seus desdobramentos possibilitam diversas análises, em âmbito nacional e internacional. O ensaio pretendeu continuar o aprofundamento dos lugares de hospitalidade, baseado nas categorias construídas por Grinover (2013), acerca de sua discussão dos elementos básicos para a interpretação da hospitalidade urbana na cidade. A cidade case objeto de estudo foi o destino turístico Campos do Jordão, localizada no estado de São Paulo (Brasil). Campos do Jordão em seu processo evolutivo ampliou sua oferta e infraestrutura turística. Pretendeu-se analisar a hospitalidade urbana, com enfoque no turismo na cidade, sendo a base às categorias: acessibilidade; legibilidade; identidade; urbanidade; qualidade de vida; e a cidadania (GRINOVER, 2007 e GRINOVER, 2013). A pesquisa utilizou-se de dados extraídos do Observatório de Turismo de Campos do Jordão. Quanto à pesquisa de campo, essa se baseou na interpretação de dados tabulados, via aplicação de um questionário de perguntas abertas, composto por cinco questões, sendo amostrados 230 questionários. No caso estudado, as interpretações iniciais sinalizam, que para o processo de hospitalidade urbana ocorra na cidade, fundamentalmente, observa-se a necessidade de uma política de hospitalidade no sentido de aproximação dos anfitriões aos espaços hospitaleiros e, ainda à aproximação dos anfitriões com os turistas, nas relações baseadas na hospitalidade comercial, frente à hospitabilidade percebida nos agentes prestadores de serviços turísticos.

Palavras-chave: Hospitalidade. Hospitalidade urbana. Hospitabilidade.

Abstract: Hospitality studies and their developments allow for various analyzes, both nationally and internationally. The essay aimed to continue the deepening of the places of hospitality, based on the categories built by Grinover (2013), about his discussion of the basic elements for the interpretation of urban hospitality in the city. The case was tourist destination Campos do Jordão, located in the state of São Paulo (Brazil). Campos do Jordão in its evolutionary process has expanded its offer and tourist infrastructure. The aim was to analyze urban hospitality, focusing on tourism in the city, being based on the categories: accessibility; readability; identity; urbanity; quality of life; and citizenship (GRINOVER, 2007 and GRINOVER, 2013). The research was based on data extracted from the Observatório de Turismo de Campos do Jordão. As for the field research, this was based on the interpretation of tabulated data, through the application of an open-ended questionnaire, composed of five questions, with 230 questionnaires being sampled. In the case studied, the initial interpretations indicate that, for the urban hospitality process to take place in the city, it is fundamentally observed the need for a hospitality policy in the sense of bringing the hosts closer to the hospitable spaces, and also to the proximity of the hosts with the tourists, at the relations based on the commercial hospitality, in front of the perceived hospitableness in the agents that offer tourist services.

Keywords: Hospitality. Urban hospitality. Hospitableness. 


\section{Introdução}

Os estudos brasileiros multiplicam-se e muitos são oriundos do Programa de Pós-Graduação em Hospitalidade da Universidade Anhembi Morumbi, e de suas parcerias e corpo egresso. Muitos são os esforços, no sentido de produzir novas interpretações aos domínios, da hospitalidade: social, comercial e doméstico (LASHLEY, 2004), e também em apurar as escolas de pensamento teórico da hospitalidade como a francesa (CAMARGO, 2004), e a escola americana (CHON; SPARROWE, 2003), a escola anglo-saxônica (LASHLEY; MORRISON, 2004). Muitas dessas pesquisas têm produzido bons resultados, e melhorado as noções de hospitalidade no Brasil, e ainda orientando muitos destinos turísticos, a explorarem as relações de vínculo humano, que a hospitalidade proporciona, na amplitude do relacionamento, entre anfitrião (quem recebe) e o turista (quem é recebido).

Os estudos da hospitalidade e seus desdobramentos possibilitam diversas análises, e trata-se de um campo de estudo que abarca várias áreas do conhecimento, atualmente exploradas constantemente pelas Ciências Sociais e Humanidades. As pesquisas do Brasil e no mundo intensificam-se e permitem novas abordagens a temáticas já relatadas desde a antiguidade.

Um esboço inicial, a luz dos lugares de hospitalidade (MENDES; FEDRIZZI, 2017a), permitiu alguns insights, frutos das categorias, da cidade hospitaleira, propostas por Grinover (2007), sendo essas: a acessibilidade, legibilidade e identidade, no caso de Campos do Jordão. Nesse sentido, a presente proposta, adequou seus instrumentos de pesquisa, orientando novos esforços, para a compreensão da hospitalidade urbana na cidade de Campos do Jordão.

A cidade de Campos do Jordão, localizada no estado de São Paulo (Brasil) destaca-se no cenário turístico nacional como destino de inverno devido às suas baixas temperaturas, o que já lhe rendeu o título de Suíça Brasileira, em função de sua semelhança com a cidade de Davos, na Suíça. Algumas características são marcantes na cidade, entre elas, seu relevo de montanhas; o céu extremamente azul devido sua altitude de $1.800 \mathrm{~m}$ do nível do mar; a riqueza na flora (Araucárias e Platanus) e fauna, e destaque especial para a arquitetura, onde se percebe uma mescla harmônica de estilos. Campos do Jordão, em seu ciclo evolutivo, passou por quatro ciclos de desenvolvimento, bem demarcados cronologicamente, estando nos dias atuais, entre o terceiro (início em 1980), denominado, ciclo do turismo, e o quarto ciclo, do meio ambiente (exploração de práticas turísticas ao ar livre).

Em seu processo evolutivo, a cidade de Campos do Jordão ampliou suas ações para receber os diversos turistas que buscam a localidade na alta temporada, o que gerou reflexos sociais e econômicas na população local. Contudo, acredita-se que a hospitalidade jordanense pode ir muito além do mero trato com o turista, pois como defende Baptista (2008), o local de residência, a paisagem envolvente, as cores, os sons e os cheiros da rua ou do bairro, as narrativas da "nossa gente", as tradições e os hábitos da "nossa comunidade", funcionam como nutrientes preciosos do caldo de humanidade que fecunda a singularidade subjetiva e faz a identidade dos lugares.

\section{Noções da hospitalidade}

A hospitalidade, em sua plenitude, permite a transformação de estranhos em hóspedes, permitindo uma aproximação e uma intensa troca de experiências. Para Camargo (2015) quatro são os conceitos que permeiam a hospitalidade, sendo eles: a relação humana; a virtude; o ritual e a troca, sendo estes grandes marcadores da hospitalidade sob a perspectiva francesa. Para Telfer (2004) a hospitalidade sempre foi considerada um santuário, no qual o anfitrião tinha a obrigação de assegurar que nenhum mal aconteceria ao seu hóspede enquanto ele estivesse sob o seu teto. Assim, para a autora, "a hospitalidade é associada à satisfação de uma necessidade, e o recebimento de convidados associase à concessão de prazer" (p.55). 
Oferecer hospitalidade aos hóspedes foi, em todos os contextos humanos, uma obrigação moral até o advento da viagem e do comércio de massa. Nessas sociedades mais modernas, a obrigação de oferecer hospitalidade ao estranho não carrega mais a mesma obrigação moral que tinha no passado. No entanto, a hospitalidade comercial atualmente oferecida poderia aprender muito com essas obrigações sociais e esses contextos antigos, constituindo-se como uma maneira de entender e de atender às necessidades do cliente e de fazer com que os visitantes se sintam bem-vindos (LASHLEY, 2015).

É neste contexto que se pode resgatar e analisar a hospitabilidade, definida por Telfer (2004, p.55) como "o nome que se dá à característica das pessoas hospitaleiras". Para a pesquisadora, a hospitabilidade seria um meio opcional de se materializar virtudes mais amplas, sendo que a pessoa escolheria esse caminho pelo prazer em receber os outros; pelo talento que tem em receber hóspedes; mas principalmente, pela atração por um ideal de hospitalidade, com base na percepção da importância emocional do lar, do acolhimento e dos benefícios especais que o ato de compartilhar pode trazer.

No cenário da hospitabilidade não basta ser hospitaleiro para tornar-se um bom anfitrião, é importante interagir segundo o conjunto de crenças que motivam o indivíduo a receber alguém e the proporcionar cortesia. No contexto comercial o anfitrião seguirá as regras sociais estabelecidas para a hospitalidade, como bem estar e conforto do cliente, acrescentando o potencial que pode ser consumido através do pagamento (Quadros, 2011). Telfer (2004) sugere que a hospitabilidade pode ser vista como um meio, entre outros, pelo qual alguém pode escolher exercer diversas virtudes mais gerais, sendo que tal conceito pode ser aplicado também ao espaço urbano e a constituição da cidade, como será explorado a seguir.

Tais termos podem ser visualizados em propagandas turísticas, como explica Bezerra (2007) ao destacar que, quando se restringe o universo aos materiais publicitários e ao marketing turístico, as expressões "cidade hospitaleira" e "cidade turística" aparecem quase sempre juntas, o que não deixa de evidenciar a fluidez entre os termos, sendo uma possibilidade que o sentido da palavra hospitaleiro, nestes casos, seja o mais cotidiano, enquanto adjetivo. Entretanto, acreditamos que, acima de tudo, a hospitabilidade só existira se o Jordanense ${ }^{1}$ se reconhecer como pertencente daquele espaço, e como tal, co-responsável pela sua preservação. Para tanto, faz-se necessário se apropriar da cidade, seguindo os conceitos de acessibilidade, legibilidade e identidade, propostos por Grinover (2007), até envolver os aspectos de qualidade de vida e cidadania propostos pelo mesmo autor em 2013.

\subsection{Acessibilidade, Legibilidade e Identidade}

Proporcionar hospitalidade aos hóspedes é tornar-se responsável por sua felicidade, enquanto eles estiverem debaixo do seu teto, um bom hospedeiro será alguém que deixará seus hóspedes felizes, enquanto estiverem sob a sua atenção (TELFER, 2004), sendo que só assim poderá ser constituída uma cidade hospitaleira.

Segundo Bezerra (2007), o entendimento de cidade enquanto tema de estudo é amplo e difuso e os conceitos buscam abranger todas as manifestações desses núcleos sociais e seu ciclo de vida. Ao longo da história, tanto a cidade medieval e suas muralhas quanto à cidade barroca com o prazer e o trabalho ou a cidade como a conhecemos hoje sempre foram espaços de possibilidades humanas e, por isso tema de interesse. O desenvolvimento das cidades e a forma de vida urbana bem caracterizam nossa civilização contemporânea. A hospitalidade enquanto dom e virtude moral está no sentido daquilo que circula entre os atores além da troca monetária. Como forma de comportamento humano, pressupõe a existência de um alguém que recebe e um alguém recebido, podendo este último ser o turista que movimenta a economia da cidade ou não, ou ainda

\footnotetext{
${ }^{1}$ Gentílico dos moradores de Campos do Jordão.
} 
um migrante. O turismo urbano pode ser apenas um dos cenários para a hospitalidade (BEZERRA, 2007).

Em proposta inicial Grinover (2006), apresenta categorias à interpretação da cidade, essas categorias apresentadas contemplaram três dimensões da hospitalidade urbana: a acessibilidade, legibilidade e identidade.

Posteriormente,

Grinover (2009a), continua suas pesquisas acerca da cidade e analisa a hospitalidade, na perspectiva do espaço urbano, incluindo a dimensão acessibilidade a mobilidade, ainda em 2009, Grinover (2009b), apresenta no seminário da Associação Brasileira de Pesquisa e Pós-Graduação em Turismo (ANPTUR), a ênfase nessa dimensão.

Contudo, gostaríamos de ir além da relação estabelecida entre o turista e a cidade, mas também englobar a visão da relação desenvolvida entre o cidadão e a cidade, pois como afirma Grinover (2013, p. 18), dando continuidade a sua pesquisa "a relação que os indivíduos mantêm com os espaços habitados se exprimem todos os dias nos modos de uso, nas condições mais banais e acidentais da vida cotidiana". Nessa perspectiva Grinover, apresenta que cidadão tem dado prioridade a uma maior possibilidade espacial, isto é, a mais escolhas locacionais proporcionados pelo aparecimento de novas formas de mobilidade, de movimentos da sociedade: expansão e fragmentação urbana. Já Sagi (2008) complementa ao destacar que as relações sociais nos centros urbanos são influenciadas por um sem número de fatores, sendo que os centros urbanos caracterizam-se por serem espaços com maior concentração de pessoas e por gerarem a necessidade de equipamentos e serviços proporcionais à este universo.

Neste espaço de contradições, a população se apropria e utiliza áreas específicas, cada qual marcada pela memória de acontecimentos, dando simbologia ao seu passado, criando uma relação com o meio físico de identidade. Esta relação gera a atratividade do local, não apenas para aqueles que ali vivem mas para aqueles que vem de fora - os visitantes e os turistas - os quais procuram em seus deslocamentos experiências singulares, o contato com o novo (SAGI, 2008, p. 92)
As dimensões apresentadas segundo Grinover (2013), em sua continuidade de esforços, quanto à hospitalidade urbana alcança novos horizontes, e nessas dimensões, existem os conceitos de acolhimento, abrigo e espaço, sendo essas: qualidade de vida, cidadania e urbanidade. Nesse sentido, outros fatores, podem ser incluídos quando relacionando a hospitalidade urbana ao turismo, como por exemplo, as acomodações, alimentação, e principalmente a boa acolhida do anfitrião. Essas categorias, agrupadas podem ser observadas no Fluxograma 1, assim percebe-se que algumas dessas dimensões ficam próximas das outras, sendo a proposta, a união da acessibilidade com a urbanidade; a legibilidade com a qualidade de vida e a identidade com a cidadania.

\section{Fluxograma 1: Categorias da cidade hospitaleira}

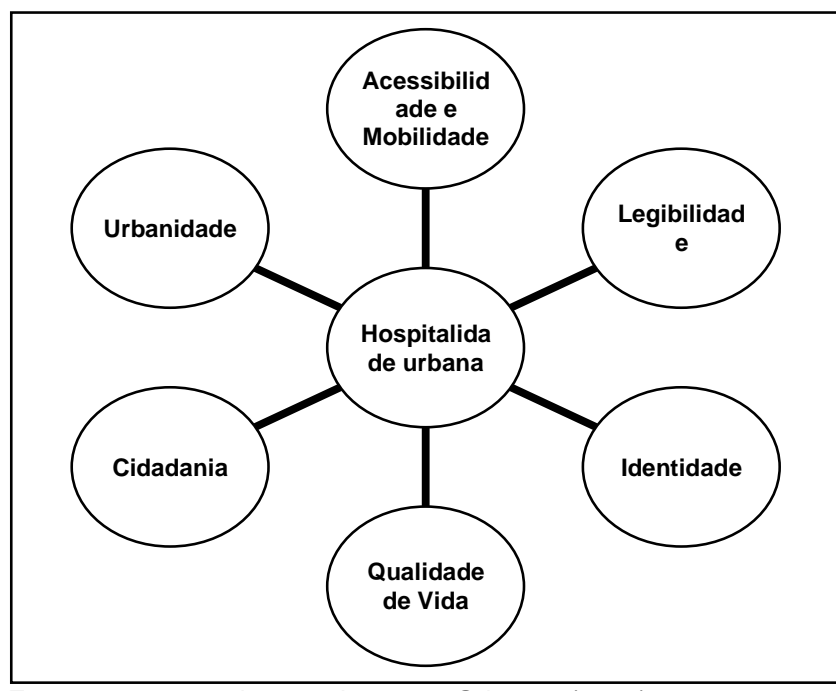

Fonte: as autoras, baseando-se em Grinover (2013).

Ao se considerar tais categorias, procura-se a construção de uma cidade hospitaleira, que reconhece a importância tanto dos visitantes, mas principalmente, dos moradores, já que são estes que exercerão a real receptividade e tornarão a experiência dos visitantes inesquecível.

\section{Campos do Jordão: a cidade e o turismo}

Campos do Jordão, cidade localizada, no estado de São Paulo (Brasil), passou por quatro ciclos de desenvolvimento, sendo que, atualmente, encontra-se entre o terceiro (início em 1980), 
denominado, ciclo do turismo, e o quarto ciclo, do meio ambiente (exploração práticas turísticas ao ar livre), estando esse ciclos de desenvolvimento sobrepondo-se e expandindo-se paralelamente.

A cidade destaca-se no cenário turístico nacional, como destino de inverno, vivendo essencialmente da prestação de serviços turísticos, e conta com ampla oferta hoteleira e gastronômica. Possui uma população fixa de 51.157 habitantes no ano de 2016, segundo o Instituto Brasileiro de Geografia e Estatísticas (IBGE), atingiu respectivamente nos anos de 2014, 2015 e 2016, 3.533.223; 3.777.321; 3.947.083, visitantes (POLÍCIA MILITAR RODOVIÁRIA SP, 2016). Os dados acerca do número de visitantes no ano de 2016 demonstra o crescimento, de 169.762 visitantes, em relação a 2015. A concentração dessa demanda turística, em relação aos meses do ano, atingiu seu ápice nos meses de maio, junho e no mês de julho (593.338 visitantes).

Dentre os segmentos do turismo, alguns deles são bem trabalhados, como o turismo de aventura, turismo gastronômico e turismo de 1 dia. Procurando melhorar os números, a Prefeitura Municipal de Campos do Jordão, em parceria com o Observatório de Turismo de Campos do Jordão, efetivou em março de 2017, um calendário de eventos, com o objetivo de fomentar o turismo e seus desdobramentos.

O calendário turístico foi planejado com a seguinte estrutura: em janeiro (Janeiro Musical); fevereiro (Carnaval de Máscaras); março (Aventura e Ecoturismo); abril (Gastronomia Mantiqueira e a Festa do Pinhão); maio (Mês da Dança); junho (Festival de Lã), julho (Festival de Inverno); agosto (Mês do Chocolate); setembro (Mês das Artes, Jazz, Blues e Vinho), outubro (Quinzena das Crianças e Quinzena Beerfest), novembro (Mês do Saber) e dezembro (Natal dos sonhos) (OBSERVATÓRIO DO TURISMO DE CAMPOS DO JORDÃO, 2017), sendo que esse calendário visa melhorar o desempenho do turismo, no município, e fidelizar seus visitantes (turistas), pelo tipo de data fixa, na programação de eventos de Campos do Jordão.
Tal preocupação com a criação de atrações decorre de diversos aspectos, como já apontados por Mendes e Fedrizzi (2017b). Segundo a Associação da Hotelaria de Campos do Jordão (ASSTUR), no ano de 2016 a taxa de ocupação hoteleira, decaiu em relação ao ano anterior em 2,68\%, onde a média entre os meses foi de $34,82 \%$. A elevação da onda sazonal deu-se nos meses de maio (43,53\%); junho $(44,50 \%)$; julho (43,51\%) e agosto (43,85\%).

$\mathrm{Na}$ perspectiva do turismo, quanto à origem dos núcleos emissores dessa demanda turística em Campos do Jordão, em 2016, segundo o Portal Receptivo, 59\% ônibus do próprio estado de São Paulo, 9\% do estado do Rio de Janeiro, e 6\% do estado de Minas Gerais, nesse sentido, prevalece o turismo regional e dos estados limítrofes ao estado origem do destino turístico, representando 74\% desse demanda. Ainda quanto a essa demanda turística recai a evidencia, que $51 \%$ fizeram City Tour com Guia no local.

Reforçando os segmentos do turismo em Campos do Jordão, em 2016, 80\% da demanda realizou o Turismo de 1 dia, a apenas $20 \%$ utilizou a infraestrutura hoteleira. Desse tipo de turismo, o turismo de 1 dia, o motivo pelo qual não se hospedaram em Campos do Jordão, segundo o Portal do Receptivo, é que $86 \%$ desses excursionistas, praticavam o Turismo Religioso, e quando questionados do local de hospedagem $72 \%$, utilizou a infraestrutura da cidade de Aparecida.

Outro fator significativo à análise do turismo, em Campos do Jordão, segundo dados coletados no Centro de Informações Turísticas (CIT), em 2016, é o motivo da viagem, e em todos os meses do ano, recai sobre o Lazer, com porcentagens superiores a $90 \%$, seguido dos Negócios e outros motivos.

Importante ainda frisar os atrativos turísticos que compõem a atratibilidade de Campos do Jordão, sendo esses apontados pela Prefeitura de Campos do Jordão, no Quadro 1, em sua maioria de propriedade particular. 
Quadro 1: Atrativos turísticos de Campos do Jordão

\begin{tabular}{|c|c|c|}
\hline ATRATIVO & CAP. MÁX. & TIPO DE PROP. \\
\hline Amantikik- Jardins que Falam & 1.000 & Propriedade Particular \\
\hline 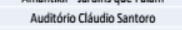 & 814 & Local püblicoco com administraçáso privads \\
\hline Aventura no Rancho & 600 & Propriedade Particular \\
\hline Borboletatrio Flores que Voam & 400 & Propriedade Particular \\
\hline Bosque do Silëncio & 200 & Propriedade Panticular \\
\hline Coss de xilograwura & 100 & Propriedade Particulat \\
\hline Casa do Artesso & 100 & Local do Estado com administraç̧o Associaç̧o \\
\hline Centro de Lazer Tarundú & 1.500 & Propriedade Particular \\
\hline Ducha de prata & 2000 & Propriedade Particular \\
\hline Estrada de Ferro Campos do Jerdao & 700 & Senvigo püblico do Estado \\
\hline Cenvejaria Baden Baden & 500 & Propriedade Particular \\
\hline Fabrica de Chocolbtes Arauctria & 700 & Propriedade Particular \\
\hline Fabbrica de Chooblates Caceu Show & 2.000 & Propriedade Particular \\
\hline 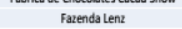 & 150 & Propiedade Particular \\
\hline Hipica Goll & & Propiriedade Particular \\
\hline Jardineiras Trenainhos da Alegria & 70 & Local püblicoco com admininstraçăo privada \\
\hline MiniGolt & 60 & Propriedade Particulat \\
\hline \multirow{2}{*}{\multicolumn{3}{|c|}{ Mosteiro Salo losa }} \\
\hline & & \\
\hline Museu fellicia Leirner & 400 & Local público com administraçó privada \\
\hline Palscio da Bas Vista & & Local püblico com administraşăo privada \\
\hline $\begin{array}{l}\text { Parque da floresta Encantrada } \\
\text { Parque das Cerejeiras }\end{array}$ & 100 & Propriedade Particular \\
\hline Parque Estadual Honto Florestal & 2000 & 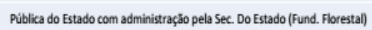 \\
\hline Passeios de Charretes & 220 & Local público com administraçăo privada \\
\hline Quad Mania & 500 & Propriedade Particular \\
\hline Quadricidos Pass Na Naturera & 300 & Propriedade Particular \\
\hline \multicolumn{3}{|l|}{ RanchosB } \\
\hline Telefterico & 2.500 & Propriedade do Estado \\
\hline Territhioio Titha & 100 & Propriedade Particilat \\
\hline Toriba Kids & 100 & Propriedade Particulat \\
\hline Truticulurur Cachoetinha & 150 & Propiriedade Particular \\
\hline Vila do a Artesanato & 1.500 & 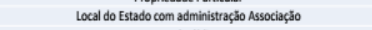 \\
\hline Vista chiness & & Local püblico \\
\hline Cenvejaria Caras de Malte & 120 & Propriedade Particulat \\
\hline
\end{tabular}

Fonte: <https://goo.gl/dje44C> (2017).

Como já apontado em outros estudos sobre Campos do Jordão, há uma preocupação com a atividade turística local, principalmente pela dependência que a cidade tem desta atividade. $O$ turismo de 1 dia vem crescendo, mas apesar do movimento, os demais setores como hospedagem e alimentação vem sofrendo uma queda de movimento, o que implica num repensar da atividade turística. É fato que a população mais jovem já vem apresentando ressalvas quanto ao turismo, como publicado por Mendes; Panza e Araújo (2016), o que afeta diretamente a sua hospitalidade, pois não se reconhecem mais como cidadãos e responsáveis por Campos do Jordão.

\section{Procedimentos Metodológicos}

O presente trabalho tem como objetivo analisar a hospitalidade urbana, com enfoque no turismo na cidade de Campos do Jordão. Apontando as categorias segundo Grinover (2007): a acessibilidade, legibilidade e identidade, e perceber as novas dimensões propostas posteriormente, Grinover (2013).
Quanto à pesquisa exploratória utilizou de dados apresentados e reunidos pelo Observatório de Turismo de Campos do Jordão, que foram apresentados publicamente no espaço Dr. Além, sendo as fontes de informação: Centro de Informações Turísticas (CIT), Associação da Hotelaria de Campos do Jordão (ASSTUR), Policia Militar do Estado de São Paulo.

Para identificar as categorias na cidade de Campos do Jordão, aplicou-se um questionário de perguntas abertas, no dia 5 de dezembro de 2016, durante o Fórum de Turismo, que ocorreu no município, nas instalações do Centro Universitário SENAC - Campos do Jordão, tendo como comissão organizadora as entidades: Secretaria de Turismo de Campos do Jordão; Campos do Jordão e Região Convention \& Visitors Bureau; Instituto Federal de São Paulo - Câmpus Campos do Jordão, Centro Universitário SENAC - Campos do Jordão e Associação das Prefeituras das Cidades Estância do Estado de São Paulo. O evento teve como temática, "Fórum de Desenvolvimento do Turismo - Campos do Jordão 2030: o futuro começa agora!". A ação deu-se em dois momentos, o primeiro ocorreu das $9 \mathrm{~h}$ ao $12 \mathrm{~h}$ (Fórum Teen), e o segundo momento das $13 \mathrm{~h} 30$ às 18h (média de 150 participantes), as inscrições foram realizadas previamente e a participação gratuita, o perfil dos participantes foi eclético, composto por: empresários, comunidade, instituições públicas e privadas, associações e convidados.

A pesquisa contou com uma amostra de 230 questionários aplicados, aos participantes do Fórum do Turismo, porém, nos questionários recolhidos, nem todas as cinco perguntas foram completadas em todos os casos. Sendo as perguntas:

- O que você costuma fazer em Campos do Jordão;

- O que você mais gosta na cidade;

- O que você menos gosta na cidade;

- O que uma pessoa não pode deixar de visitar em Campos do Jordão;

- O que caracteriza a identidade de Campos do Jordão. 
Como fundamentação teórica buscou-se na literatura a temática da hospitalidade dessa forma, foram analisados as categorias de Grinover (2007): acessibilidade, legibilidade e identidade, sob a perspectiva da hospitalidade urbana, e sua relação com a hospitabilidade, complementando-se com a qualidade de vida, urbanidade e cidadania, incorporados pelo autor em 2013.

\section{Resultados e discussão}

A primeira variável de análise para mensurar as categorias propostas por Grinover (2007) teve como objetivo interpretar a legibilidade urbana, mensurando-a através dos locais de convívio, sendo a pergunta: $\mathbf{O}$ que você costuma fazer em Campos do Jordão? Essa variável obteve 227 unidades. Deste total, foi possível estratificar 34 frentes interpretativas, e apenas 18 dessas respostas atingiram frequência superior a duas incidências, assim, o Gráfico 1, a seguir, apresenta essas 18 frentes. Para efeito de significação, as respostas, nos casos: gastronomia, esporte, residente, lazer e turismo se tratam de um ajuste, metodológico interpretativo, para a criação de frentes expandidas. Nesse sentido, na frente gastronomia foram agrupadas as respostas (restaurante, jantar, almoçar, bares, comer fora), no esporte (correr, andar, caminhar, tracking), no residente (pessoas, amigos e visitar familiares), no lazer (passear, andar de bicicleta, show, academia, andar, aventura, diversão e eventos) e turismo (turismo de aventura, trilha, pontos turísticos e ecoturismo).

\section{Gráfico 1: 0 que você costuma fazer em Campos} do Jordão

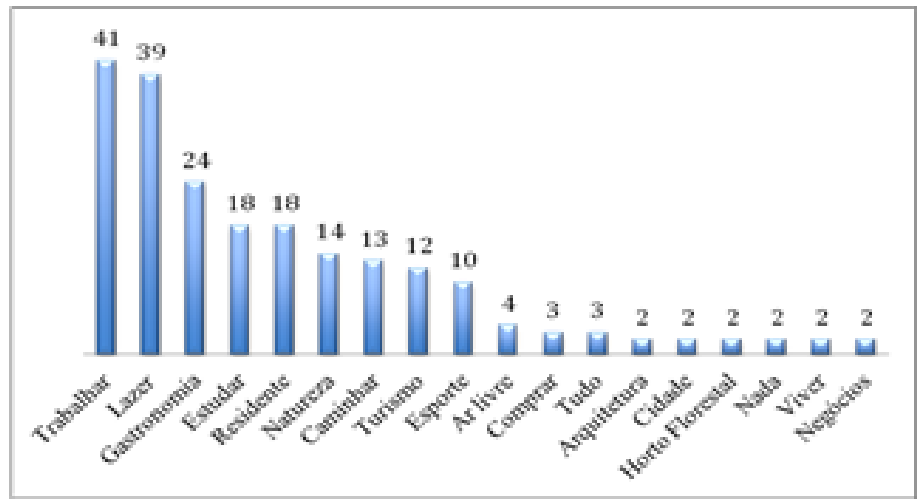

As primeiras impressões acerca da categoria da cidade hospitaleira, a legibilidade, refletem por meio desse estudo a imagem mental, que dela fazem, como sendo um local de trabalho para os seus habitantes, e ao mesmo tempo um espaço voltado para o lazer, remontando a dualidade de sentidos o trabalho (estudo) versus o espaço de lazer (turismo, caminhar, esporte), e ainda, com forte atrativo a alimentação, lugares de hospitalidade, com muito ar livre e natureza. Tais respostas, ainda possibilitam a dinâmica da relação entre a legibilidade dos espaços que os cidadãos utilizam sendo a cidade seu local de trabalho, e também, a aproximação com a qualidade de vida, no sentido do seu ócio ser criativo com atividades de lazer.

A frente trabalhar, vem repleta de significados, muitos deles ocultos, e que podem passar despercebidos, como por exemplo, a relação do trabalho, sendo esse trabalho principalmente a atividade turística em Campos do Jordão, no relacionamento como a hospitalidade comercial, porém, nesse ponto recai as inquietações da hospitalidade, como sendo, algo onipresente na vida humana, e a hospitabilidade, como a vontade e disposição dos habitantes em prestar serviços hospitaleiros, uma vontade genuína, que pode ser exercida pelo seu tipo de trabalho.

\section{A segunda pergunta: $\mathbf{O}$ que você mais gosta}

na cidade? Pretendeu verificar a categoria acessibilidade, onde, o acesso dos indivíduos, as atividades, lugares e serviços disponíveis em Campos do Jordão. Essa variável obteve 189 unidades. Deste total, foi possível estratificar 9 frentes interpretativas, e apenas 7, dessas respostas atingiram frequência superior a 2 incidências, conforme Gráfico 2. 


\section{Gráfico 2: O que você mais gosta na cidade}

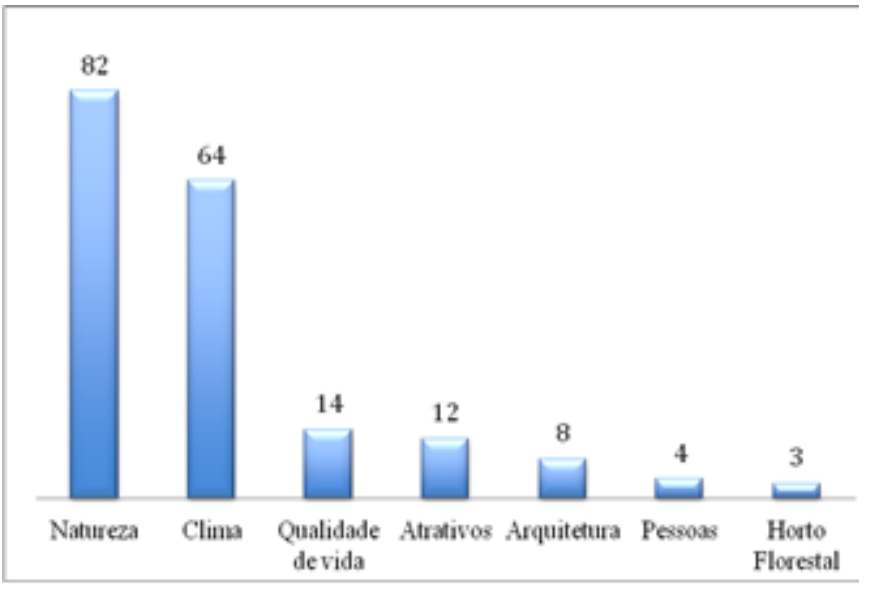

Quanto ao processo de adequação das frentes interpretativas do Gráfico 2, a adequação deu-se: para natureza (paisagem, montanhas, fauna e flora; água), para o clima (frio e ar limpo), para a qualidade de vida (calmaria, segurança e tranquilidade), nos atrativos (gastronomia; atividades radicais, passeios, Pico do Itapeva, trilhas, Tarundú, turismo de aventura, patrimônio, patrimônio histórico e Capivari).

Das respostas, evidencia-se que $78 \%$ delas indicam fatores ligados ao ambiente, $10 \%$ desse total, relaciona-se com o fator humano, $8 \%$ são os atrativos da cidade e entre eles, o Horto Florestal, o Pico do Itapeva, o Tarundú e o Capivari, e ainda, 4\% reflete a interpretação visual da cidade com sua diversidade arquitetônica.

$\mathrm{Na}$ exploração dos resultados torna-se necessário revelar a apresentação real, da nova dimensão, a qualidade de vida, como resposta direta, das 14 (unidades) do total de 189 respostas.

O Gráfico 3, representa a pergunta: 0 que você menos gosta na cidade, a pergunta acima, quando projetada, foi realizada de forma ampla e geral, sendo que, após a análise dos dados, a sua compreensão remete aos aspectos de acessibilidade, o que permite ou impede o cidadão de ocupar e viver a cidade em sua plenitude.

\section{Gráfico 3: O que você menos gosta na cidade}

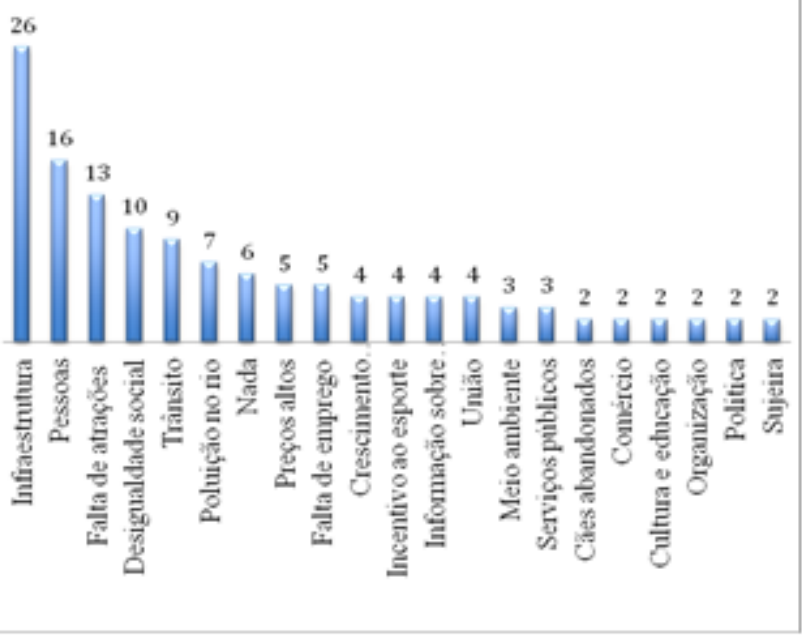

O processo de adequação das frentes interpretativas para Gráfico 3, foram: Falta de atrações (cinema, opções de lazer e eventos); Infraestrutura (acesso, iluminação, acessibilidade, abandono, lixo, mobilidade e sinalização); Hospitalidade (desrespeito); pessoas (fechadas para amizades, não usufruem dos espaços públicos, qualificação da mão de obra e descaso). As frentes expostas atingiram a frequência superior a duas incidências.

A hospitalidade urbana quando relacionada à acessibilidade (mobilidade), prima 0 acesso dos cidadãos aos serviços e infraestrutura ofertada pela cidade, e ainda a igualdade aos seus acessos, nesse sentido a desigualdade social destacou-se na amostra que totalizou apenas 147 repostas a essa pergunta.

O fator que mais incomoda a população amostrada foi à falta de infraestrutura na cidade, relacionado a esse fator, outras respostas como: o trânsito, os serviços públicos e a falta de atrações. Curiosamente, a frente, cães abandonados apareceu com 2 incidências.

A quarta variável, a pergunta: 0 que uma pessoa não pode deixar de visitar em Campos Jordão? Essa variável obteve 199 unidades. Deste total, foi possível estratificar 34 frentes interpretativas, e apenas 22 dessas respostas atingiram frequência superior a duas incidências, podem ser observadas no Gráfico 4. 


\section{Gráfico 4: 0 que uma pessoa não pode deixar de visitar em Campos Jordão}

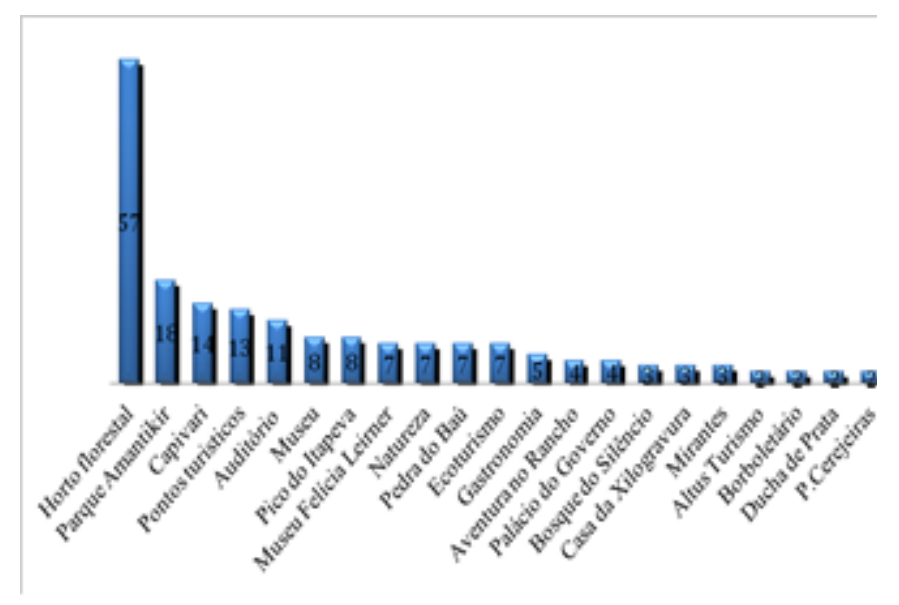

Os ajustes metodológicos necessários, ocorreram para as frentes: gastronomia (restaurantes e café) e ecoturismo (trilhas e turismo de aventura).

Percebe-se a grande influência do turismo, pois, 15 das frentes interpretativas são atrativos turísticos. O objetivo dessa pergunta era verificar a categoria identidade, e percebe-se a aproximação com os lugares turísticos como lugares de hospitalidade. Os lugares de hospitalidade, segundo Baptista (2008, p. 6), "lugares de hospitalidade" são lugares de urbanidade, de cortesia cívica, de responsabilidade e de bondade. São lugares nossos que convidam à entrada do outro numa oferta de acolhimento, refúgio, alimento, ajuda ou conforto". Esses espaços, no caso de Campos do Jordão em sua maioria são lugares turísticos, que propiciam a hospitalidade para seus visitantes. E também são atrativos turísticos, onde os moradores não pagam uma taxa turística para a visitação, e assim este pode exercer a hospitalidade para seus convidados, assumindo o papel de anfitrião em todos os cenários, como por exemplo, no cenário da hospitalidade doméstica, porém, nas relações fundamentadas na troca mercadológica, ou seja, a hospitalidade comercial, o residente enquanto anfitrião tem a possibilidade de exerce a hospitabilidade nata, devido as suas experiências anteriores e além disso, a identificação com esse ambiente, através do reconhecimento prévio do atrativo. Ressalta-se as premissas do vínculo da hospitabilidade exercida com amplo apreço nos espaços reconhecidos pelos moradores enquanto prestadores de serviços turísticos, possibilitando conforto e prazer nessa prática comercial.

Nesse sentido a identidade, quando analisada na vertente da hospitalidade urbana, fundamenta-se na cidadania, não no seu sentido superficial no status, porém, e sim na cidadania da aproximação do convívio territorial, transformando esses espaços (atrativos) em seus e ao mesmo tempo conseguindo dividi-los com outras pessoas (turistas). Porém é oportuno frisar que existem cidades hospitaleiras, "[...] e cidades inóspitas, onde desigualdade e conflitos marcam a configuração dos espaços que se tornam hostis, ilegíveis, inseguros, narrando histórias de violência e exclusão" (GRINOVER, 2013, p. 20).

E por fim, a quinta pergunta: $O$ que caracteriza a identidade de Campos do Jordão, teve em sua essência, o anseio de perceber os laços criados pela cidade nos que nela habitam. Obtiveram-se 214 unidades de análise a essa variável, onde foi possível criar 23 frentes de interpretação, dessas 17 frentes podem ser observados no Gráfico 5, com frequência superior a duas incidências. Os ajustes de adequação das frentes interpretativas há: charme (glamour, requinte e luxo), gastronomia (restaurante) e qualidade de vida (segurança, tranquilidade, simplicidade e ar puro).

Consecutivamente aparece a qualidade de vida, em Campos do Jordão. A qualidade de vida na cidade consiste em um grande desafio, pois, envolve considerar suas facetas. Essas facetas são afetadas por ações como, a política pública, a administração da urbe, e ainda, a apropriação dos espaços públicos da cidade pela comunidade. Esses elementos afetam sobremaneira a interpretação de como a comunidade participa da vida social, e das interações que essas irão gerar, provavelmente, esses elementos irão contribuir para que os cidadãos percebam a cidade frente a uma cidade hospitaleira, uma cidade agradável. 
Gráfico 5. O que caracteriza a identidade de Campos do Jordão

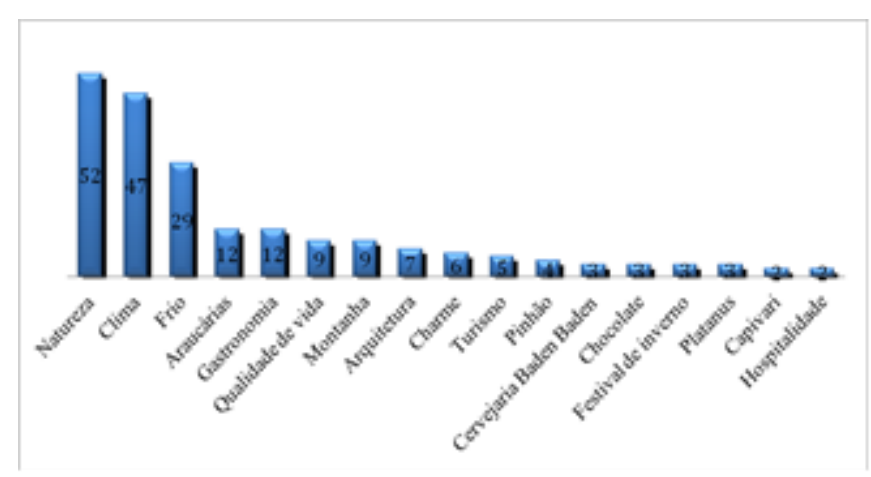

Novamente fatores relacionados ao ambiente, na cidade são representativos com $73 \%$ das respostas, sendo os fatores: natureza, clima, frio, Araucárias, montanha e Platanus. Curiosamente aparecem dois alimentos que influenciam a atividade turística, com o pinhão e o chocolate, e também o Festival de Inverno, evento tradicional que faz parte do calendário turístico, que ocorre no mês de julho.

Sendo a hospitalidade essencialmente geradora de vínculos humanos a qualidade de vida, engloba as necessidades humanas de bem estar, individual e coletivo, via percepção sensorial, englobando a paisagem urbana, destacando-se os fatores ligados há: limpeza, iluminação, preservação da flora e fauna, água potável, atrativos que possibilitem o lazer desse residente, não apenas atrativos voltados à atividade turística.

\section{Considerações finais}

Campos do Jordão é uma cidade repleta de áreas verdes, com clima agradável, e diversidade de atrativos turísticos. Seus espaços urbanos foram criados para atender as exigências da demanda turística e gerar renda para os investidores, evidenciando a falta de infraestrutura nos bairros simples da cidade, onde os atrativos e a oferta turística são escassos. Esta constituição permite a clara percepção de uma desigualdade e a predominância de conflito de interesses, sendo estes aspectos que marcam a dinâmica da hospitalidade urbana da cidade.
As categorias propostas por Grinover (2013) englobam todas as facetas da cidade e seus desdobramentos, porém, no caso da cidade analisada, para que a hospitalidade urbana ocorra fundamentalmente, observa-se a necessidade de uma política de hospitalidade no sentido de aproximação dos anfitriões aos espaços hospitaleiros, já que, em sua maioria, são espaços turísticos, pois a cidade em sua essência vive dessa atividade.

Ainda acredita-se que muitos desses anfitriões que trabalham diretamente na prestação de serviços turísticos basearam suas escolhas nesse ramo, pois, são indivíduos hospitaleiros que buscam também, na prática do trabalho, incluir suas iniciativas espontâneas que a hospitalidade genuína propicia a geração de vínculos humanos. Nesse sentido reside à aproximação do anfitrião com os turistas, e essa relação de cunho comercial justifica-se frente à hospitabilidade percebida nos agentes prestadores de serviços turísticos de Campos do Jordão.

Os números demonstram que a cidade continua a receber um grande número de visitantes e por isso urge o debate sobre a hospitalidade $\mathrm{e}$ hospitabilidade. Principalmente quando se analisa os dados e se percebe o crescimento do Turismo de 1 dia e um decréscimo dos índices de hospedagem. Esta situação já começa a provocar uma ruptura na qual a cidade e o jordanense se dividem entre 0 trabalho e o espaço que consideram ser do turista e não deles. Contudo, pensando na qualidade de vida e na construção da cidadania, como Grinover (2013) aponta, alguns locais não cobram ingressos do morador local, sendo o Horto um destes, o que incentiva o morador a se apropriar da cidade.

Reforça-se que a apropriação da cidade pelo morador é a base necessária para que a hospitalidade urbana se efetive, garantindo uma sustentabilidade da atividade turística, permitindo uma convivência mais harmônica entre anfitriões e visitantes. 


\section{Referências}

BAPTISTA, Isabel. Hospitalidade e eleição intersubjectiva: sobre o espírito que guarda os lugares. Revista Hospitalidade. São Paulo, v. 5, n. 2, p. 5-14, 2008.

BEZERRA, S.R.Z.S. Apontamentos sobre hospitalidade, turismo e modernidade. Revista Cesumar, jul-dez., v.12, n.2, p.335-345, 2007.

CAMARGO, L.O. Hospitalidade. São Paulo: Aleph, 2004.

CAMARGO, L.O. Os interstícios da hospitalidade. Revista Hospitalidade. São Paulo, ano 5, XII, n. especial, maio, p. 42-69, 2015.

CHON, K.S.; SPARROWE, R.T. Bem vindo à indústria da hospitalidade. In:

Hospitalidade: conceitos e aplicações. São Paulo: Pioneira Thomson Learning, 2003, p. 226.

GRINOVER, Lucio. A hospitalidade na perspectiva do espaço urbano. Revista Hospitalidade. São Paulo, ano VI, n. 1, p. 4-16, 2009.

GRINOVER, L. Hospitalidade, qualidade de vida, cidadania, urbanidade: novas e velhas categorias para a compreensão da hospitalidade urbana. Revista Iberoamericana de Turismo, vol. 3, n. 1, p.16-24, 2013.

MENDES, B.C; FEDRIZZI, V.L.P. O perfil do turista na cidade de Campos do Jordão, sob a ótica dos lugares de hospitalidade. In: Invtur 2017 (Conferência Internacional), 17 a 19 de maio (prelo). Universidade de Aveiro, Portugal, $2017 a$.

MENDES, B.C; FEDRIZZI, V.L.P. Ciclo de vida do turismo em Campos do Jordão: uma análise sob a perspectiva da interface hoteleira. In:
Forúm Abratur 17, 7 a 9 de junho (prelo). Departamento de Hotelaria e Turismo da Universidade Federal de Pernambuco (UFPE), Recife, 2017b.

MENDES, B.C; PANZA, T.; NEVES, T. Um olhar sobre a formação identitária em cidades turísticas: breve análise sobre Campos do Jordão. In: Seminário Nacional de Pesquisa e Pós-Graduação em Turismo (ANPTUR), Anais, XIII, 28 a 30 de setembro. São Paulo, 2016.

QUADROS, A. H. A hospitalidade e o diferencial competitivo das empresas prestadoras de serviço. Revista Hospitalidade. São Paulo, vol. VIII, n. 1, p. 43-57, jan.-jun. 2011.

LASHLEY, C. Para um entendimento teórico. In: LASHLEY, C; MORRISON, A. (orgs.). Em busca da hospitalidade: perspectivas de um mundo globalizado. São Paulo: Manole, 2004, p. 3-24.

LASHELY, C. Hospitalidade e Hospitabilidade. Revista Hospitalidade. São Paulo, vol. XII, n. especial, maio, p. 70-92, 2015.

SAGI, Luciana. Gestão pública da hospitalidade urbana: estudo de caso do Parque da Água Branca na cidade de São Paulo. Revista Brasileira de Pesquisa em Turismo. v. 2, n. 3, p. 90-105, nov. 2008.

TELFER, E. A filosofia da "hospitabilidade". In: LASHLEY, C.; MORRISON, A. Em busca da hospitalidade: perspectivas para um mundo globalizado. Barueri (SP): Manole, 2004. p. 5378. 